\title{
DYNAMIC CERVICAL MR IMAGING FINDINGS OF PATIENTS WITH HIRAYAMA DISEASE IN A TERTIARY CARE HOSPITAL OF NORTH-EAST INDIA
}

\author{
Tralukya Nandan Sonowal1, Sushant Agarwal2, Hrishikesh Choudhury3 \\ ${ }_{1}^{1}$ Assistant Professor, Department of Radiology, Gauhati Medical College and Hospital, Guwahati, Assam. \\ ${ }^{2}$ Registrar, Department of Radiology, Gauhati Medical College and Hospital, Guwahati, Assam. \\ ${ }^{3}$ Assistant Professor, Department of Radiology, Gauhati Medical College and Hospital, Guwahati, Assam.
}

\section{ABSTRACT}

\section{BACKGROUND}

Juvenile muscular atrophy of the distal upper limb (Hirayama disease) is a rare disease, predominantly affecting the anterior horn cells of the cervical spinal cord in young men. Most studies of Hirayama disease have been conducted in Asia, particularly Japan. To characterise the MR imaging findings of patients of North-East India with HD, we reviewed neutral and flexion cervical MR imaging examinations performed for suspected patients with possible HD at tertiary care hospital in North-East India.

\section{MATERIALS AND METHODS}

We assessed the MR imaging examinations with clinical correlation in young males with weakness and hand muscle wasting retrospectively for LOA (Loss of Attachment) of the posterior dura to the spine, cervical spinal cord atrophy, spinal cord T2 hyperintensity, loss of cervical lordosis, anterior dural shift with flexion in patients from 2014 to 2017. These patients were also evaluated electrophysiologically.

\section{RESULTS}

Twenty-four patients met the criteria for HD. All were males of different ethnic background, predominantly in the persons engaged in lifting/ pulling heavy objects. Findings of HD were often present on neutral images, but the addition of flexion images increased diagnostic confidence. All patents were males less than 30 years of age. All (100\%) had oblique amyotrophy, 9 (37.5\%) had fasciculations and $6(25 \%)$ had cold paresis. Electromyography (EMG) showed chronic denervation in C7 - T1 myotomes. NCS (Nerve conduction study) showed reduced compound muscle action potential (CMAP) in median and ulnar compound muscle in nine patients. Neutral position MRI showed loss of cervical lordosis (100\%), localised lower cervical cord atrophy (100\%) and intramedullary hyperintensity (60\%). Flexion study showed loss of dural attachment, anterior displacement of dorsal dura and epidural flow voids (90\%) and enhancing epidural crescent in (90\%).

\section{CONCLUSION}

Young males of North-East India with clinical HD corroborated well with electrophysiological diagnosis of anterior horn cells disease. While the findings often present on neutral and flexion MR images, as dynamic contrast MR imaging findings is characteristic should be performed. Prognosis of the disease progression runs benign course with early diagnosis and help in early treatment modalities.

\section{KEYWORDS}

Hirayama Disease, Dynamic Flexion Magnetic Resonance Imaging, Monomelic Amyotrophy.

HOW TO CITE THIS ARTICLE: Sonowal TN, Agarwal S, Choudhury H. Dynamic cervical MR imaging findings of patients with Hirayama disease in a tertiary care hospital of North-East India. J. Evolution Med. Dent. Sci. 2018;7(16):1993-1998, DOI: $10.14260 /$ jemds/2018/448

\section{BACKGROUND}

Hirayama disease is a rare condition characterised by a symmetric muscle weakness and atrophy in the C8-T1 distribution with a self-limiting course.(1) It is classically presenting initially as progressive weakness in adolescent males, stabilising over several years. Hirayama differs from the known types of motor neuron diseases, because of its non-progressive behaviour and pathologic findings of focal ischaemic changes in the anterior horn of the lower cervical cord.

'Financial or Other Competing Interest': None.

Submission 26-03-2018, Peer Review 05-04-2018,

Acceptance 09-04-2018, Published 16-04-2018.

Corresponding Author:

Dr. Sushant Agarwal,

Registrar of Radiology,

Gauhati Medical College and Hospital,

Guwahati-781032, Assam.

E-mail: sushantgmc@rediffmail.com

DOI: $10.14260 /$ jemds $/ 2018 / 448$

\section{(c) (i) $\$$}

The pathomechanism is not well understood; however, the prevailing theory postulates that insufficient growth of the dura relative to the spinal column during puberty allows forward displacement of the dura in flexion of the spinal cord, possibly leading to ischaemia of the anterior horn cells at C8 and T1.(2) Most cases have been reported from Asia, particularly Japan,(1) though some cases reported from Middle East and Europe.(3-6) In the literature, various magnetic resonance imaging features have been described for the diagnosis of this disease entity. MR imaging findings reported in patients from South-East Asia and Japan include loss of attachment (LOA) of the dura to the lamina, asymmetric lower cervical spinal cord atrophy, spinal cord T2 hyperintensity, loss of cervical lordosis in the neutral position and forward displacement of the dura with flexion MR imaging. (7)

\section{Aims and Objectives}

In the present study, the different MRI findings are summarised and their distributions among the population from North-East India are evaluated. 


\section{MATERIALS AND METHODS}

- The present study was carried out in the Department of Radiology, Gauhati Medical College and Hospital.

- The retrospective observational study was carried out during a period from January 2014 to January 2017.

- The resultant study population consisted of 24 patients referred from Neurology Department. The cases were selected on the basis of clinical suspicion.

All the patients were clinically assessed. In all the cases thorough history was taken including presenting complaints, duration and progression of symptoms, personal history (including occupation etc.), medical history and treatment history if any.

- All the patients were studied, recorded according to the proforma.

- Patients were included in the study had undergone routine and dynamic contrast enhanced MRI.

- $\quad$ All the patients underwent electrophysiological tests.

MRI system using Siemens Tim Avanto 1.5 Tesla machine images were obtained with a body coil and an adapted protocol for the cervical spine with flexion studies. Echo T2, MR myelogram in sagittal and coronal planes. The sequences performed in normal position and hyperflexion of cervical spine included Sagittal SE T1W with and without fat saturation, TSE T2, Gradient Echo T2 and MR myelogram in sagittal and coronal planes. Post-contrast SE T1W was done in transverse and sagittal planes. Maximal possible hyperflexion of neck was achieved by asking the subject to move the head forward close to chin touching the chest. The shoulders were pushed as far caudal as possible. The position was maintained by supporting the neck and shoulders with MR-compatible foam pads. The gadolinium-based MR contrast agent was used in the dose of $0.5 \mathrm{mmol} / \mathrm{kg}$ and was administered as bolus intravenously. Imaging features were retrospectively analysed according to MR features of cervical cord appearance, attachment of dural sac and contrast enhancement pattern.

\section{RESULTS}

The study was carried out in the Department of Radiodiagnosis, Gauhati Medical College and Hospital for a period of 3 years from January 2014 to January 2017.

Patients referred to the department with clinical suspicion of Hirayama disease were studied. The patients were evaluated MRI without and with intravenous contrast media. Imaging features of total number of 24 cases were evaluated. All the cases were also evaluated with electrophysiological tests.

\section{Inclusion Criteria}

Cases with hand weakness with muscle wasting coming from North Eastern region of India were included in the study.

\section{Exclusion Criteria}

Cases occurring from intervertebral disc-related compressive myelopathy, traumatic, transverse myelitis were excluded from analysis.

The Results observed in the Present Study were-

Age Incidence- In this study group of 24 patients, the various age groups were as follows:

\begin{tabular}{|c|c|c|}
\hline Age in Years & No. of Patients & Percentage (\%) \\
\hline $11-20$ & 6 & $25 \%$ \\
\hline $21-30$ & 18 & $75 \%$ \\
\hline \multicolumn{3}{|c|}{ Table 1 } \\
\hline
\end{tabular}

So, the maximum number of cases were seen in the $3^{\text {rd }}$ decade numbering 27 cases.

\section{Sex Distribution}

In our present series of 24 patients, all the patients were male and no females.

\begin{tabular}{|c|c|}
\hline Heavy weight workers & $11(45.8 \%)$ \\
\hline Non-heavy workers & $13(54.2 \%)$ \\
\hline \multicolumn{2}{|c|}{ Table 2 } \\
\hline
\end{tabular}

\section{Clinical Presentations}

\begin{tabular}{|c|c|}
\hline Symptoms and Signs & No. of Cases \\
\hline Hand weakness & 24 \\
\hline Forearm weakness & 24 \\
\hline Hand wasting & 21 \\
\hline Forearm Muscle wasting & 13 \\
\hline Cold paresis & 6 \\
\hline Brachioradialis sparing & 24 \\
\hline Minipolymyoclonus & 9 \\
\hline Brisk deep tendon reflexes & 2 \\
\hline Bilateral involvement & 13 \\
\hline Unilateral involvement & 11 \\
\hline Fasciculation & 9 \\
\hline Dysaesthesia on hand & 2 \\
\hline \multicolumn{2}{|c|}{ Table 3} \\
\hline
\end{tabular}

\section{RESULTS}

24 patients fulfilled the clinical criteria. Thus, neutral position MRI was done in all 24 patients and flexion contrast MRI was done in all the patients.

\section{Clinical Features}

All the patients were males with median age of 22.5 years (range 10 - 30 years) at the time of clinical examination. Patients belonged to North-East India. All patients were less than 30 years of age, one patient presented as early as at 15 years of age. The duration of illness at the time of presentation was 3 months to 3 years. 5 patients had symptoms for less than 1 year, 9 had symptoms between 1 and 2 years and 10 had symptoms between 2 and 3 years.

All patients presented with insidious onset of progressive weakness and lower motor neuron type of wasting of one or both hands. Seven $(29 \%)$ patients presented with right-sided, four $(16 \%)$ with left-sided and rest thirteen (54\%) presented with bilateral asymmetric weakness and wasting. None of the patients had neck pain or radicular symptoms.

All $(100 \%)$ had oblique amyotrophy, six $(25 \%)$ cold paresis, 9 (37.5\%) minipolymyoclonus and 9 (37.5\%) had fasciculations. None had Horner's syndrome. Regional reflexes were variably absent. Two patients had brisk reflexes of lower limbs. Plantars were flexors and sensory examination was normal in all patients. 


\section{MRI Findings}

Localised lower cervical cord atrophy was seen in 9/11 $(82 \%)$ of the suspected cases of HD. Asymmetric cord flattening was noted in all $11(100 \%)$ cases. Loss of cervical lordosis was seen in 10/11 (91\%), loss of dural attachment in 9/10 (90\%), anterior displacement of dorsal dura on flexion in $9 / 10(90 \%)$ and epidural flow voids were seen in $9 / 10$ (90\%) cases. Enhancing epidural crescent in flexion was seen in all $10 / 10(100 \%)$ cases who underwent dynamic study. Intramedullary hyperintensity was seen in $2 / 11(18 \%)$ cases. Distinctive MRI features are shown in Figures 1 - 3.

\begin{tabular}{|c|c|}
\hline Neutral Position & \\
\hline $\begin{array}{c}\text { Abnormal cervical curvature } \\
\text { (loss of cervical lordosis) }\end{array}$ & $24(100 \%)$ \\
\hline Localised lower cervical atrophy & $23(95.8 \%)$ \\
\hline Asymmetric cord flattening & $11(45.8 \%)$ \\
\hline $\begin{array}{c}\text { Intramedullary hyperintensity in lower } \\
\text { cervical cord }\end{array}$ & $16(66.6 \%)$ \\
\hline Table 4 \\
\hline
\end{tabular}

\begin{tabular}{|c|c|}
\hline $\begin{array}{c}\text { Flexion Position } \\
\text { sac and lamina }\end{array}$ & $24(100 \%)$ \\
\hline $\begin{array}{c}\text { Anterior shifting of posterior dural wall on } \\
\text { flexion }\end{array}$ & $24(100 \%)$ \\
\hline $\begin{array}{c}\text { Prominent epidural flow voids } \\
\text { region }\end{array}$ & $18((75 \%)$ \\
\hline \multicolumn{2}{|c|}{ Table 5 } \\
\hline \multicolumn{2}{|c|}{$21(87 \%)$} \\
\hline
\end{tabular}

\section{Electrophysiology Tests}

NCS and EMG were done in all the patients within 1 week of the clinical examination. Median and ulnar compound muscle action potentials (CMAPs) were reduced in the nine patients, and ulnar CMAP was reduced in fourteen patients. However, distal latencies and $\mathrm{F}$-wave latencies were within the normal range. Conduction velocities were normal in all nerves. Sensory NCS was normal in all the patients. EMG revealed features of active denervation in the form of fibrillations in five patients and fasciculations in nine patients and features of chronic denervation in the form of neurogenic changes in C7, C8 and T1 myotomes in all the patients. EMG of C5, C6 myotomes namely deltoid, biceps brachii and brachioradialis was normal.

\section{Electrophysiological Examination}

\begin{tabular}{|c|c|c|}
\hline Sl. No. & Examination & Percentage (\%) \\
\hline 1 & Median CMAP decreased & $9(37 \%)$ \\
\hline 2 & Ulnar CMAP decreased & $14(58 \%)$ \\
\hline 3 & $\begin{array}{c}\text { Sensory nerve action potential } \\
\text { in median and ulnar nerves }\end{array}$ & $\begin{array}{c}\text { Normal in all } \\
\text { patients }\end{array}$ \\
\hline 4 & $\begin{array}{c}\text { Distal and F-wave latencies in } \\
\text { median and ulnar nerves }\end{array}$ & $\begin{array}{c}\text { Normal in all } \\
\text { patients }\end{array}$ \\
\hline 5 & $\begin{array}{c}\text { NCV median and ulnar motor } \\
\text { and sensory nerves }\end{array}$ & $\begin{array}{c}\text { Normal in all } \\
\text { patients }\end{array}$ \\
\hline 6 & Fibrillation & $5(20 \%)$ \\
\hline 7 & Fasciculations & $9(37.5 \%)$ \\
\hline \multicolumn{2}{|c|}{ Table 6 } \\
\hline
\end{tabular}
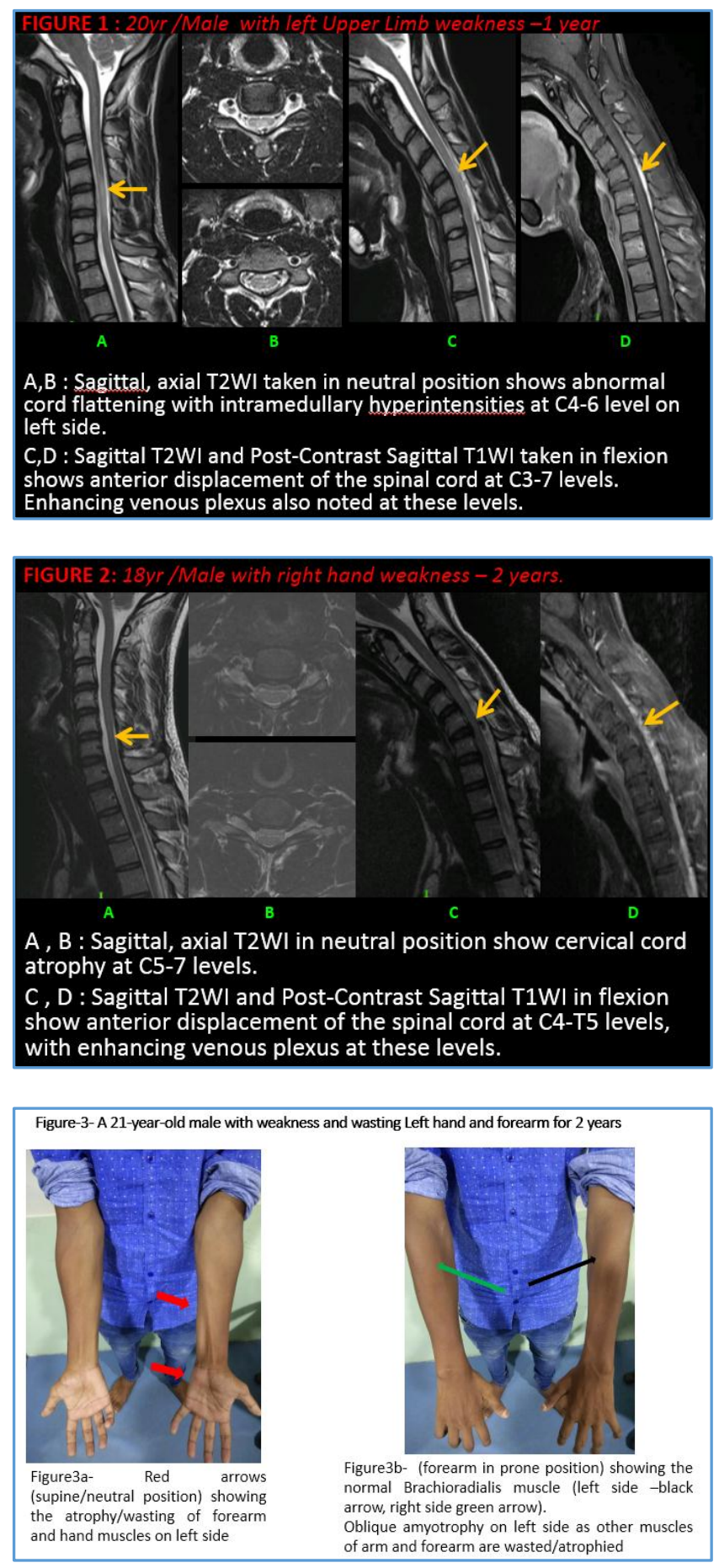

\section{DISCUSSION}

HD is a benign disorder with a stationary stage after a progressive course for up to 6 or fewer years. It occurs mainly in young males between the ages of 15 and 25 years. ${ }^{[8]}$ All our patients were younger than 30 years. Eleven (45.8\%) patients were engaged in works related to heavy weights like weight lifting, farming and working in lifting heavy weights. Though, it has not been correlated in studies published before. We suggest that works related to pulling or lifting heavy weights in early age may have strong association with the disease onset or progression.

The clinical features include insidious onset, predominantly unilateral upper extremity weakness and atrophy, cold paresis and no sensory or pyramidal tract involvement. $[5,9,10]$ The amyotrophy is unilateral in most patients, asymmetrically bilateral in some and rarely 
symmetric in others.[11] Eleven of our patients presented with unilateral and thirteen patients presented with bilateral asymmetric weakness and wasting of the hands and forearms. The clinical findings in our study are correlating with a greater proportion of the patients showing the characteristic abnormalities of HD with the studies by Hasan et al (2012),[11] Sonwalkar et al[9] and Raval et al.[5]

Although, Hirayama et al first reported this disease in 1959, pathologic study was not possible until 1982 because of its benign course.[12,13] At pathologic examination shrinkage, necrosis and gliosis were found in the anterior horns of the spinal cord from C5 to T1, particularly marked at C7 and C8.[12] However, the underlying pathogenesis of the disease was not known until 1987 when Kikuchi et al first proposed tight dural canal as the underlying predisposing factor.[14] Atopy and elevated serum IgE level have been postulated to be precipitating factors in HD. $[15,16]$

An imbalanced growth resulting in disproportional length between the patient's vertebral column and spinal canal contents has been suggested as the cause of a tight dural sac and anterior displacement of posterior dural wall when the neck is flexed.[14,17,18] The different growth rates between male and female patients have been proposed by Toma et al to be the factor related to the male preponderance of HD.[19] The disproportionate shortening of the dural sac is perhaps accentuated during the juvenile growth spurt, explaining the preponderance in adolescence.[19]

In patients with HD, conventional radiographic studies of the cervical spine may show loss of cervical lordosis.[18] Myelography is difficult to perform, because it is not easy to retain the contrast medium in the cervical subarachnoid space when the neck is flexed.[10] MRI with flexion contrast study is the gold standard of diagnosis. The findings reported more frequently are asymmetrical or symmetrical atrophy of lower cervical cord, prominence and enhancement of posterior epidural venous plexus on flexion studies and anterior shifting of posterior dural sac on flexion. Loss of attachment between the posterior dural sac and subjacent lamina on neutral position, anterior shifting of the posterior wall of cervical dural canal enhancing epidural crescentic mass in the lower cervical and thoracic region and prominent posterior epidural flow voids suggestive of dilated epidural venous plexus on flexion studies are reported as highly suggestive for the diagnosis of HD. [10,17,18,20]

Among the imaging features discussed above, localised lower cervical cord atrophy, asymmetric cord flattening and loss of attachment have an accuracy of $80 \%$ in identification of the disease; loss of attachment has been proposed as the most valuable finding for diagnosing HD in the neutral position. ${ }^{[7,21]}$ In our study, localised lower cervical cord atrophy and loss of cervical lordosis were seen in over $90 \%$ of the cases of HD. In earlier studies, Hirayama and Tokumaru have reported this in only $50 \%$ of their cases. Pradhan and Gupta found focal cord atrophy in neutral neck position on MRI in $100 \%$ of their cases.[2,17] Asymmetric cord flattening was noted in eleven cases (45.8\%). Loss of dural attachment, anterior displacement of dorsal dura in all of the cases and epidural flow voids on flexion were seen in eighteen (75\%) of the cases. Enhancing epidural crescent in flexion was seen in twenty one (87\%) cases who underwent dynamic study. Our findings are comparable to the findings of Hasan et al,[11] Raval et al[5] than that of Sonwalkar et al.[9] Such variation is likely due to the difference in patient's characteristics and extent of disease.

The most important pathogenetic factor probably is compression of spinal cord by tight dura. Hirayama et al in their studies on 73 patients revealed that dynamic compression of the lower cervical cord due to forward displacement of the posterior cervical dural sac and spinal cord on neck flexion was confined to an early and progressive stage of the disease. However, Pradhan and Gupta from their study on 35 patients showed that both spinal cord and posterior dura mater move forward independently under a longitudinal stretch and that the forward displacement of the dura mater was not responsible for the cord compression.[22]

Venous congestion in flexion might also play an additional role in determining spinal cord ischaemic changes.[23] The proposed mechanisms for venous engorgement seen on flexion studies is due to increased flow to posterior internal vertebral venous plexus resulting from the negative pressure in posterior spinal canal as a result of anterior shifting of dural canal and decrease in drainage of jugular veins impeding venous return of internal vertebral venous plexus.[21] Additionally, the compressed anterior internal vertebral venous plexus caused by anterior displacement of dural canal increases the burden of posterior internal vertebral venous plexus leading to its distension.[10,21] Pradhan and Gupta have postulated that the overstretched posterior dura mater that forcefully moves forward during neck flexion results in negative space behind, which appears on MRI as congested epidural space.[22] Posterior dura mater came forward in all their patients, resulting in a dilated crescent-shaped epidural space.[22] Dilated crescent-shaped epidural space was seen in all our patients who underwent dynamic study.

Although, a diagnosis of HD is straightforward at flexion MR imaging, the challenge for radiologists is how to identify this condition on routine non-flexion MR studies.[10] To ensure that this diagnosis is not missed in patients presenting with focal hand wasting, flexion contrast MRI should be done if the routine MRI otherwise looks normal and if MND has been excluded. Several conditions like syringomyelia, MND, cervical spondylotic myelopathy, spinal cord tumour and traumatic myelopathy may cause localised amyotrophy of the distal arm and these should be excluded first by imaging modalities.[19]

From our cases, we found that asymmetry is one of the most characteristic findings of this disease, both clinically and radiologically. Thus, in cases of adolescent onset of distal upper limb weakness, the finding of asymmetric cord atrophy on routine non-flexion MR studies, especially at the lower cervical cord should raise the suspicion of HD. When this finding is seen, flexion MR study should be performed to confirm the diagnosis.[9,10]

In electrophysiological studies of our patients NCS of median and ulnar nerves were normal, while decreased CMAP in 14 (58\%) cases. EMG of the upper cervical myotomes was normal, while that of the lower cervical myotomes showed active and/ or chronic denervation in all patients. While the clinical-electrophysiological profile was suggestive of anterior horn cell disease, dynamic flexion MRI of the cervical spine supports the theory of forward dural shift causing lower cervical cord compression and ischaemia of anterior horns. 
Monomelic amyotrophy has been traditionally subclassified under the idiopathic group of MND seen in India.[24] Young patients with unilateral upper limb atrophy have been classically labelled brachial MMA, which represent cases of HD. Gourie-Devi et al found in their study from 1977 through 1981, 13 patients with single upper limb atrophy. The clinical description of these patients with single upper limb atrophy reported by Gourie-Devi et al is similar to the clinical profile of HD described by Hirayama et al.[8,25] Pradhan et al in their series of 106 patients of HD seen from 1992 to 2008 reported around $10 \%$ of all the patients to have bilaterally symmetric involvement, a severe form of classic HD which remains undiagnosed due to a common notion that it is a unilateral or grossly asymmetric disease. These cases of brachial monomelic amyotrophy represent HD. [26]

Our study has several limitations. The retrospective design precluded the ability to recruit an age-matched group without HD. For the purposes of this study, we evaluated MR imaging findings at only one time point for patients with HD; however, in our experience and that of Hirayama and Tokumaru, ${ }^{2}$ the severity of MR imaging findings can change with time.

\section{CONCLUSION}

$\mathrm{HD}$, a rare disease affecting young men in the second to third decades of life, is characterised by insidious onset and slowly progressive course followed few years later by static phase of unilateral or asymmetric atrophy of the hand(s) and forearm(s) with sparing of the brachioradialis characterised as oblique amyotrophy. It is thought to be a cervical flexion myelopathy related to repeated movements of the neck causing chronic microcirculatory changes in the territory of the anterior spinal artery supplying the anterior horns of the lower cervical cord. While dynamic contrast MRI is characteristic of HD, routine MRI has a high predictive value for diagnosis.

\section{REFERENCES}

[1] Tashiro K, Kikuchi S, Itoyama Y, et al. Nationwide survey of juvenile muscular atrophy of distal upper extremity (Hirayama disease) in Japan. Amyotroph Lateral Scler 2006;7(1):38-45.

[2] Hirayama K, Tokumaru Y. Cervical dural sac and spinal cord in juvenile muscular atrophy of distal upper extremity. Neurology 2000;54(10):1922-6.

[3] Blumen SC, Drory VE, Sadeh M, et al. Mutational analysis of glycyl-tRNA synthetase (GARS) gene in Hirayama disease. Amyotroph Lateral Scler 2010;11(1-2):237-9.

[4] Cerami C, Valentino F, Piccoli F, et al. A cervical myelopathy with a Hirayama disease-like phenotype. Neurol Sci 2008;29(6):451-4.

[5] Raval M, Kumari R, Dung AAD, et al. MRI findings in Hirayama disease. Indian $\mathrm{J}$ Radiol Imaging 2010;20(4):245-9.

[6] Schroder R, Keller E, Flacke S, et al. MRI findings in Hirayama's disease: flexion-induced cervical myelopathy or intrinsic motor neuron disease? J Neurol 1999;246(11):1069-74.
[7] Chen CJ, Hsu HL, Tseng YC, et al. Hirayama flexion myelopathy: neutral-position MR imaging findingsimportance of loss of attachment. Radiology 2004;231(1):39-44.

[8] Hirayama K. Juvenile muscular atrophy of unilateral upper extremity (Hirayama disease)-half-century progress and establishment since its discovery. Brain Nerve 2008;60(1):17-29.

[9] Sonwalkar HA, Shah RS, Khan FK, et al. Imaging features in Hirayama disease. Neurol India 2008;56(1):22-6.

[10] Chen CJ, Chen CM, Wu CL, et al. Hirayama disease: MR diagnosis. AJNR Am J Neuroradiol 1998;19(2):365-8.

[11] Hassan KM, Sahni H, Jha A. Clinical and radiological profile of Hirayama disease: a flexion myelopathy due to tight cervical dural canal amenable to collar therapy. Ann Indian Acad Neurol 2012;15(2):106-12.

[12] Hirayama K, Tomonaga M, Kitano K, et al. Focal cervical poliopathy causing juvenile muscular atrophy of distal upper extremity: a pathological study. J Neurol Neurosurg Psychiatry 1987;50(3):285-90.

[13] Hirayama K, Toyokura Y, Tsubaki T. Juvenile muscular atrophy of unilateral upper extremity: a new clinical entity. Psychiatr Neurol Jpn 1959;61:2190-8.

[14] Kikuchi S, Tashiro K, Kitagawa M, et al. A mechanism of juvenile muscular atrophy localized in the hand and forearm (Hirayama's disease)--flexion myelopathy with tight dural canal in flexion. Rinsho Shinkeigaku 1987;27(4):412-9.

[15] Kira J, Ochi H. Juvenile muscular atrophy of the distal upper limb (Hirayama disease) associated with atopy. J Neurol Neurosurg Psychiatry 2001;70(6):798-801.

[16] Chen TH, Hung CH, Hsieh TJ, et al. Symmetric atrophy of bilateral distal upper extremities and hyperIgEaemia in a male adolescent with Hirayama disease. J Child Neurol 2010;25(3):371-4.

[17] Pradhan S, Gupta RK. Magnetic resonance imaging in juvenile asymmetric segmental spinal muscular atrophy. J Neurol Sci 1997;146(2):133-8.

[18] Mukai E, Sobue I, Muto T, et al. Abnormal radiological findings in juvenile-type distal and segmental muscular atrophy of upper extremities. Rinsho Shinkeigaku 1985;25:620-6.

[19] Toma S, Shiozawa Z. Amyotrophic cervical myelopathy in adolescence. J Neurol Neurosurg Psychiatry 1995;58(1):56-64.

[20] Hirayama K. Non-progressive juvenile spinal muscular atrophy of the distal upper limb [Hirayama's disease]. In: De Jong JM, editor. Handbook of clinical neurology. Vol. 15. Amsterdam, the Netherlands: Elsevier, 1991:107-20.

[21] Mukai E, Matsuo T, Muto T, et al. Magnetic resonance imaging of juvenile-type distal and segmental muscular atrophy of upper extremities. Rinsho Shinkeigaku 1987;27(1):99-107.

[22] Pradhan S, Gupta RK. Cervical dural sac and spinal cord in juvenile muscular atrophy of distal upper extremity. Neurology 2001;56(4):575. 
[23] Ciceri EF, Chiapparini L, Erbetta A, et al. Angiographically proven cervical venous engorgement: a possible concurrent cause in the pathophysiology of Hirayama's myelopathy. Neurol Sci 2010;31(6):845-8.

[24] Velmurugendran CU, Srinivasan AV. Motor neuron disease in tropics. In: Chopra JS, Sawhney IM. (eds). Neurology in tropics. New Delhi: Elsevier, Division of Reed Elsevier India, 2004:437-44.
[25] Gourie-Devi M, Suresh TG, Shankar SK. Monomelic amyotrophy. Arch Neurol 1984;41(4):388-94.

[26] Pradhan S. Bilaterally symmetric form of Hirayama disease. Neurology 2009;72(24):2083-9. 